\title{
PLANNING OF HEAT SUPPLY OF TERRITORIES: MODEL AND ALGORITHMS
}

\author{
Ekaterina E. Mednikova ${ }^{1, *}$ \\ ${ }^{1}$ Melentiev Energy Systems Institute of Siberian Branch of the Russian Academy of Sciences (ESI \\ SB RAS), Pipeline Energy Systems Department, 130, Lermontov str., Irkutsk, Russia, 664033
}

\begin{abstract}
The choice of direction of heat supply systems development in cities is an important task for the authorities, district heating companies and consumers. The author focuses on two main problems in heat supply development questions: territory zoning by type of heat supply and determination of economically feasible heat supply systems sizes. For the solution of these problems, the mathematical model and algorithms were developed. For the solution of this task algorithms were developed.
\end{abstract}

\section{Introduction}

District heating (DH) is wide spread in Russia, because there are special climatic and economic conditions for its development and implementation in this country. DH covers more than $70 \%$ of heat energy consumption. It is necessary for all settlements where DH systems operate to develop and approve the scheme of heat supply to ensure efficient and reliable development of heat supply system(HSS).

Last years, the requirements to quality and reliability of heat supply were changed. The regulatory documents for Russian heat supply systems were adopted, such as the Russian Law "On heat supply" [1] and "Requirements to heat supply schemes" [2]. The analysis of regulatory and legal framework shows that problems of energy planning are important. Many reasons led to necessity to review approaches for planning of heat supply development [3]. Considering the above, it's necessity to make complex assessment of all competitive variants to choose the type and capacity of $\mathrm{DH}$ system, to increase its efficiency and reliability. In this case, several problems must be solved, these are task of territory zoning by type of heat supply, justification of optimal size of HSS and concentration of heat sources capacities. The transition to innovative solutions in the field of heat supply $[4,5]$, creation of the intelligent HSS are impossible without effective planning of HSS development and taking reliability [6] and consumers requirements into consideration.

In Russia, heat supply planning is not so developed like in Europe, especially in the Scandinavian countries [2-4, 7-14]. The basis of heat supply planning are presented in works $[7-9,15]$. Besides, the importance of aforementioned problems is mentioned in other countries $[16,17]$. The use of existing European approaches doesn't guarantee a reliable solution for Russian HSSs for many reasons, for example, different technical solutions and

\footnotetext{
* Corresponding author: yakimetse@isem.irk.ru
} 
characteristics of heating system; different climatic conditions and specifications and technical documentation [18].

This work continues and develops the basic provisions of previous works [3, 19] and it's based on the Theory of Hydraulic Circuits [20]. The author proposed several algorithms to carry out the territory zoning by type of heat supply and to justify economically feasible heat supply systems' sizes.

\section{Heat supply planning model}

\subsection{Heat supply planning objective}

Proposed heat supply planning technique allows to find optimal solution for two main problems. These are territory zoning by type of heat supply and search of economically feasible size of a DH system. Three mathematic models were worked out. The first is for complex heat supply development planning and two others [3] are for solving the problems individually. This paper presents the complex technique.

The objective of the heat supply planning model is to minimize the total cost of heat supply including generation cost, transmission and distribution costs.

$$
C^{H S S}\left(Q, x, t, q_{S}, q_{L}\right)=C^{D H S}\left(Q, x, t, q_{S}, q_{L}\right)+C^{I N D}(Q, t) \rightarrow \min \quad t \in T
$$

where $C^{H S S}$ - total cost of heat supply (EUR), $C^{D H S}$ - total cost of DH (EUR), $C^{I N D}$ - total cost of individual heating (EUR), $Q$ - heat load (MW), $x$ - a heat carrier flow at the sections of heat supply system's network $(\mathrm{t} / \mathrm{h}), q_{S}$ is the boundary value of heat load density $(\mathrm{MW} / \mathrm{km} 2), q_{L}$ is the boundary value of linear heat density $(\mathrm{GJ} / \mathrm{m}), t$ is an index for years in the scheduling horizon.

The objective includes the annual investment planning and operation costs associated with generating units (CHP, heat-only boilers, and individual heat units) and heat pipelines for systems with an equal energy effect. Total cost of $\mathrm{DH}$ includes the cost of heat production, heat transmission and distribution and additional specific investment cost for increasing of heat source capacity in DH system [21]. Total cost of individual heating includes fuel costs and additional specific investment cost for the unit of individual heating.

The heat supply planning model includes the system of constraints and conditions [3]: energy balance between heat production and heat consumption, capacity constraints for heat sources in $\mathrm{DH}$ systems and individual units, equations for calculation of the flow distribution in hydraulic circuit, equation that describes correlation between a mass flow rate and a heat load, conditions imposed by requirements of heat supply reliability [19], which are defined by standard values of nodal indices of reliability, equations for estimation of boundary values of heat density criteria $q_{S}$ and $q_{L}$, equation for estimation of actual value of heat load density per unit area, equation for estimation of an actual value of linear heat density (for transmission pipes).

Condition of district's connection to DH system (2):

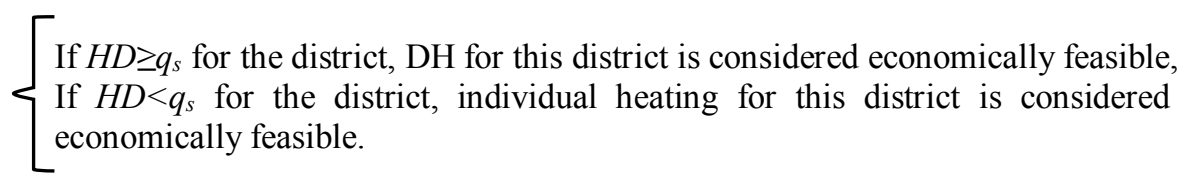

where $H D$ is an actual value of heat load density for selected district $\left(\mathrm{MW} / \mathrm{km}^{2}\right)$.

The actual value of linear heat density should be higher than the normative value:

$$
L H D_{i} \geq q_{L i}
$$


where $L H D_{i}$ - an actual value of linear heat density for $i$-th heat source $(\mathrm{GJ} / \mathrm{m}), i$ is an index for heat sources in $\mathrm{DH}$ zone.

Nonlinear programming methods are used to solve the optimization problem.

If the problems need to be solved separately, their objective functions can be expressed according to the Ref.[3]:

objective function for territory zoning by type of heat supply

$$
C^{H S S}\left(Q, x, t, q_{S}\right)=\sum_{i} C_{S_{i}}^{D H S}(Q, t)+\sum_{m} C_{H N_{m}}\left(x, t, q_{S}\right)+\sum_{n} C_{n}^{I N D}(Q, t) \rightarrow \min
$$

$i \in I, m \in M, n \in N, t \in T$

objective function for determination of economically feasible size (scale) of DH system

$$
\begin{aligned}
& C^{H S S}\left(Q, x, t, q_{L}\right)=\sum_{i} C_{S_{i}}^{D H S}(Q, t)+\sum_{m} C_{H N} H\left(x, t, q_{L}\right) \rightarrow \min \\
& i \in I, m \in M, t \in T
\end{aligned}
$$

where $C_{S_{i}}^{D H S}, C_{H N}, C_{n}^{I N D}$ are total costs for heat sources in DH zone, heat network in DH system and individual heating units (EUR).

\subsection{Heat supply planning algorithms}

The complex technique for heat supply planning of cities territory has been divided into two algorithms for usability like it's presented in Fig.1.



Fig. 1. Sequence of the solution of HSSs development problems

The algorithm №1 includes the following steps:

1. Organization of Data base, including territorial planning, buildings types, expected heat loads of consumers, etc.

2. Development of forward variants of the territory division according to the Urban plan. This step means the selection of districts of perspective development where it is necessary to organize heat supply.

3. Calculation of these districts' area. 
4. Calculation of consumers' heat loads in the perspective districts.

5. The choice of comparable sources (for DH system and individual heating) and input technical and economic information of these heat sources.

6. Calculation of the actual value of heat load density per area unit for selected districts.

7. Calculation of the boundary value of heat load density per area unit $q_{S}$ for comparable heat sources, Ref. [3].

8. Estimation of collected actual values of heat load density with regard to the boundary value $q_{S}$ and zoning territory by types of heat supply.

8.1. If actual value of heat load density for selected district is higher than the boundary value, the considered district belongs to the $\mathrm{DH}$ zone.

8.2. If actual value of heat load density for selected district is lower than the boundary value, the considered district belongs to the individual heating zone.

9. Check of feasibility of heat balance.

10. Check of capacity constraints for heat sources in DH systems and individual units.

11. This step depends on the problem statement.

11.1. Calculation of the objective function (4) if the problem of territory zoning by type of heat supply needs to be solved separately.

11.2. The transition to the implementation of the algorithm №2 if the problem needs to be solved comprehensively.

The second algorithm is the algorithm for size determination of DH system. It has an objective function (5) if the problem needs to be solved separately.

The algorithm №2 includes the following steps:

1. Organization of Data base for DH zones, including existing network topology, node and pipe variables, etc.

2. Choosing of heat sources and its location. Here you can choose existing CHP plants and heat-only boilers or new heat sources to cover the power deficit.

3. Calculation of heat loads for each considered heat sources. At this stage, it is necessary to take into account all consumers on considered period.

4. Calculation of the flow distribution in hydraulic circuit (hydraulic calculation).

5. Check of feasibility of heat balance.

6. Check of capacity constraints for heat sources in DH systems.

7. Calculation of transmission pipes' length and the actual value of linear heat density for considered heat sources.

8. Calculation of the boundary value of linear heat density $q_{L}$ for considered heat sources, Ref. [3].

9. Comparison of collected actual values of linear heat density with boundary values $q_{L}$ and preliminary evaluation of $\mathrm{DH}$ systems sizes.

9.1. If linear heat density for selected heat source and connected to it consumers is higher than the boundary value, considered consumers belong to the operation zone of this heat source (go to the step 10).

9.2. If linear heat density for selected heat source and connected to it consumers is lower than the boundary value, this DH system should be divided into several small DH systems for increasing of actual linear heat density up to boundary value. This can be done by consecutive disconnection of the most removed consumers or by redistribution of loads among sources. Return to the step 2 if you need to choose another heat source or to the step 3 if you don't need to choose another heat source.

10. Check of conditions imposed by requirements of heat supply reliability, which are defined by standard values of nodal indices of reliability.

10.1. In case of violation of the constraints, duplication of pipeline sections and connectors between pipelines must be added. Also you can increase reliability by redistribution of loads among sources. Return to the step 2 . 
10.2. Go to the next step if requirements are satisfied.

11. This step depends on the problem statement.

11.1. Calculation of the objective function (5) if the problem of size determination of DH system needs to be solved separately.

11.2. Calculation of the objective function (1) if the problem needs to be solved comprehensively.

\section{Case study}

The case study example presented in this section illustrate application of the proposed heat supply planning model for Shelehov city with population over 47 thousand (Irkutsk region, Russia), see Fig. 2. HSS includes one CHP (heat power - $404 \mathrm{MW}$ ) with transmission and distribution heat pipelines and 1383 dwelling houses with individual heat installations with total heat load about $60 \mathrm{MW}$. The length of transmission pipes is $15.7 \mathrm{~km}$.

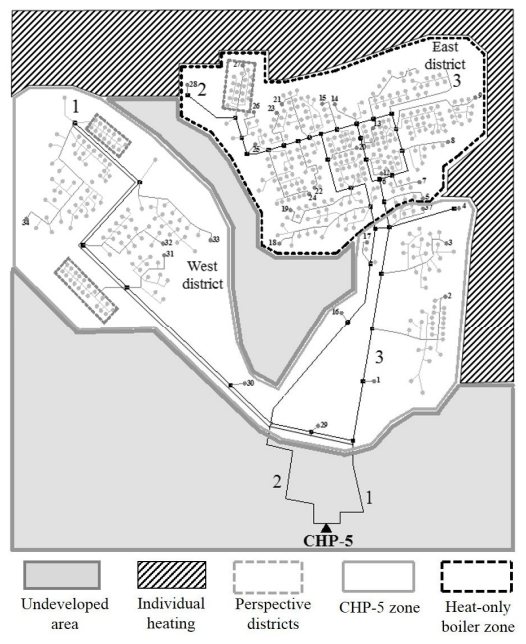

Fig. 2. The heat supply scheme of Shelehov city.

The case study results are compared and analyzed based on the objective function (1) because we need to solve both problems of DH system's development and take into account the reliability requirements. Territory zoning by type of heat supply is carried out based on the algorithm №1. Fig. 2 shows zones of district and individual heating. Individual heating zone is districts with heat load density less than $22 \mathrm{MW} / \mathrm{km}^{2}$. Analysis of DH system's economic feasibility is based on the algorithm №2.

The findings of the analysis indicate that DH zone should be divided into two systems with different heat sources. The first system is the West district and part of the East district and existing CHP, the second system is a new heat-only boiler and part of consumers of the East district. According to the results, new consumers located within the received zones have to be connected to the relevant systems. According to preliminary estimates, the organization of heat supply under the new scheme taking into account the allowable reduction in the heat production for CHP-5 will reduce the total costs by $15 \%$, and the specific costs of heat energy distribution will be reduced by $14 \%$.

\section{Conclusion}

The mathematical model and algorithms oriented to modern conditions of HSSs 
development are offered for the solution of heat supply planning problems. The importance of the offered mathematical statement is the possibility to use it at the stage of predesign researches for preliminary assessment of directions of heat supply systems development. The offered mathematical model includes restrictions for heat load density, which allow to reduce the number of variables in the calculated schemes. On the one hand, the findings in this paper allow to plan development of the heat supply systems reasonably. On the other hand, the results create good conditions for more detailed calculations for the choice of optimal composition of heat sources, their capacities and types, and also a configuration of the heat network and parameters of its elements.

\section{Acknowledgements}

The research was performed at Melentiev Energy Systems Institute SB RAS in the framework of the scientific project III.17.4.3 №AAAA-A17-117030310437-4 of the foundation researches program of SB RAS.

\section{References}

1. Federal Law of the Russian Federation N 190-FZ of 27.07.2010 «On heat supply»

2. The Governmental order № 154 of 22.02.2012 «On requirements to heat supply schemes, the order of their development and approval».

3. V.A. Stennikov, E.E. Iakimetc, Energy, 110, 157-165 (2016)

4. H. Lund, S. Werner, R. Wiltshire, S. Svendsen, J.E. Thorsen, F. Hvelplund, B.V. Mathiesen, Energy, 68, 1-11 (2014)

5. J. Ziemele, A. Gravelsins, A. Blumberga, D. Blumberga, Energy Proceedia, 95, 522527 (2016)

6. V.A. Stennikov, I.V. Postnikov, In: Vasant P., Voropai N.I., editors. Sustaining power resources through energy optimization and engineering (Hershey PA: Engineering Science Reference (an imprint of IGI Global)), 102-126 (2016)

7. IEA. District heating distribution in areas with low heat demand density. SenterNovem (2008)

8. K. Sperling, F. Hvelplund, B.V. Mathiesen, J. Energy Policy, 39, 1338-1351 (2011)

9. U. Persson, S. Werner, J Applied Energy, 88, 568-576 (2011)

10. K. Hansen, D. Connolly, H. Lund, D. Drysdale, J.Z. Thellufsen, Energy, 115, 1663$1671(2016)$

11. B. Möller, H. Lund, Applied Energy, 87, 1846-1857 (2010)

12. U. Persson, S. Werner, Applied Energy, 88, 568-576 (2011)

13. S. Nielsen, B. Möller, Energy, 57, 458-468 (2013)

14. L. Grundahl, S. Nielsen, H. Lund, B. Möller, Energy, 115, 1771-1778 (2016)

15. S. Frederiksen, S. Werner, District heating and cooling. (Studentlitteratur AB, 2013)

16. Z. Huang, H. Yu, Energy and Buildings, 71(7), 103-111 (2014)

17. G. Mendes, C. Ioakimidis, P. Ferrao, Ren. and Sust. Energy Rev., 15, 4836-4854 (2011)

18. A. Nuorkivi, Advanced District Heating and Cooling (DHC) Systems. (Woodhead Publishing is an imprint of Elsevier, 2016), 17-41

19. V.A. Stennikov, I.V. Postnikov, J Power Technology and Engineering, 47(6), 446-453 (2014)

20. A.P. Merenkov, V. Ya. Khasilev, The Theory of hydraulic circuits, (Moscow, Nauka,. 1985) (in Russian)

21. V.A. Stennikov, E.E. Mednikova, Thermal Engineering, 63(9), 657-665 (2016) 